\title{
Essential Use Cases in the Design of Multi-channel Service Offerings - A Study of Internet Banking
}

\author{
Lia Patrício ${ }^{1}$, J. Falcão e Cunha ${ }^{2}$, Raymond P. Fisk ${ }^{3}$, and Oscar Pastor ${ }^{4}$ \\ ${ }^{1}$ Faculdade de Engenharia da Universidade do Porto \\ Rua Dr. Roberto Frias, 4200-465 Porto, Portugal \\ lpatric@fe.up.pt \\ ${ }^{2}$ Faculdade de Engenharia da Universidade do Porto \\ Rua Dr. Roberto Frias, 4200-465 Porto, Portugal \\ jfcunha@fe.up.pt \\ ${ }^{3}$ College of Business Administration - University of New Orleans \\ New Orleans, LA 70148-1566, USA \\ rfisk@uno.edu \\ ${ }^{4}$ Dept. de Sistemas Informáticos y Computación - Univ. Politécnica de Valencia \\ Camino de Vera, Apartado 22012, 46020 Valencia, España \\ opastoradsic.upv.es
}

\begin{abstract}
This article presents the results of a qualitative study of a multichannel bank. It aims at developing new methods of gathering user requirements for web interfaces, joining HCI and Marketing perspectives. The results obtained so far indicate that, as most of financial operations are functionally available in the different service channels, experience requirements become increasingly important. In this context, essential use cases are particularly valuable in improving the process of gathering customer requirements. As they allow the analysis of users' interaction needs in a channel-independent way, their use can improve decisions on what services are best suited to each channel, to effectively address customer needs across different interaction modes, and make an efficient allocation of resources among channels.
\end{abstract}

\section{Introduction}

The widespread commercial use of the Internet for self-service provision has created a new environment in which interfaces are designed for a wide set of potential customers, with diversified user and usage profiles, and little technology orientation. This situation has created an increased need for accurate methods of requirements gathering for wide and diverse groups of customers, which analyze the interface in the context of overall service provision.

This study aims at developing new methods of gathering user requirements for web interfaces, joining UCD and Services Marketing approaches. It started with a qualitative study of the customers of a multi-channel bank, which provides services through high street branches (BB), telephone (TB), ATM and the Internet (IB). The research work began with 14 in-depth interviews and 4 focus groups with bank customers, and 1 focus group and 3 in-depth interviews with bank staff, in an overall total of 49 interviewees.

Following qualitative methods, the sample of customers was not designed to be statistically representative of the population, but was purposefully defined according 
to theoretical relevance of cases [1] of both users and non-users of Internet Banking. The interviews were transcribed and analyzed via the qualitative software NUD*IST (www.qsr.com.au/products/n6.html).The qualitative research aimed to elicit the potential factors driving or inhibiting the usage of Internet banking, which can be used for the identification of interface requirements. The results were also used to design a survey, with the objective of testing the generalization of the exploratory findings, and measuring the impact of the different influence factors on customers' decisions to use the Internet banking service.

\section{Customer Experience Requirements and Internet Services}

As the Internet becomes a mature technology, requirements gathering should include both technical and market requirements, and both Interaction Design and Marketing perspectives are needed [2]. HCI research has produced several measures of user interface usability. These studies have produced guidelines on the most important usability goals, such as time to learn, speed of performance, rate of errors, and user retention [3], simplicity, clarity of function, and visibility [4]. However, given the critical influence of perceived quality and satisfaction in the adoption and usage of new interfaces, it seems that further effort should be made to improve the methods of elicitation of experience requirements. Customer experience requirements are related to user experience goals, and differ from usability goals as they are concerned with how users experience an interactive product from their perspective [5].

Service quality research can also provide useful insights in the identification of customer experience requirements. The upsurge of the Internet has motivated several researchers to develop measures of web service quality, such as e-SERVQUAL [6] and Webqual [7]. Theses studies identified the dimensions of e-service quality in the customers' words, such as efficiency, fulfillment, reliability and privacy (eSERVQUAL); ease of use, usefulness, entertainment and complementary relationship with other channels (WebQual).

In this study, it is clear that customers do not express their preferences for each channel so much with technology features and functionalities, but with the service experience they can get. In the customers' perspective, Internet banking is usually seen as a more efficient interaction in terms of higher accessibility, convenience, ease of use and time saving. IB also performs well in terms of usefulness of functionalities, quality and deepness of information, autonomy and feed-back control.

The perceived service experience appears to be a key determinant of IB usage. IB security concerns and the negative issues associated with new technologies in general seem to be the main reasons why non-technology customers avoid it. On the other hand, its positive performance in terms of efficiency seem to motivate time poor, technology oriented customers to use it, in spite of security concerns and a certain degree of depersonalization.

\section{Essential Use Cases and Customer Experience Requirements}

Use cases have been extensively applied in software development to describe the interaction between a user and an interface [8]. However, it is important to distinguish 
between concrete use cases, which assume a previously defined interface and interaction design, and essential use cases, which describe users' intentions of interaction, and system's responsibilities, in a technology free and implementation-independent way [9]. The Marketing framework, especially the Consumer Behavior area, also provides tools to categorize and understand experience requirements for the different essential use cases. In service provision, use cases may be characterized in terms of the type of decision process, which is related to perceived risk, complexity, and frequency [9]. On the other hand, several stages of consumer decision and consumption process can be identified: problem recognition, information search, evaluation of alternatives, product choice and product usage [9]. Identifying the type and the stage of consumer decision process to which a use case belongs may help in identifying the most relevant experience requirements.

In this study, data analysis and categorization allowed the identification of relevant use cases of interaction between the customer and the bank, the associated customer needs or requirements, and the channels regularly used in each case. The consumer decision framework provided tools to categorize essential use cases and to understand the most relevant experience requirements for each one of them.

The results indicate that each essential use case is associated with different experience requirements, which influence strongly interaction choice [11]. The type of decision process influences strongly channel choice, as it generates specific needs. In the interviewees' perspective, financial operations which are considered routine, unimportant, low risk, and well known by customers - such as current account transactions - are usually undertaken in the IB, or other automatic channel, although they are also available in the bank branch. For these kinds of financial operations, customers give priority to the efficiency attributes of the Internet, such as convenience, ease of use, time saving and accessibility. For complex, unknown, important operations such as mortgage loans - customers prefer the personal interaction in the bank branch, as this channel is associated with mutual knowledge, individualized attention, and professional competence of employees, which customer's value in these situations.

The study results also show that, for the same financial product, customers use different channels according to the stage of product usage. Information gathering for decision or monitoring purposes may be performed through the Web, even for mortgage loans. However, negotiation and contracting are usually undertaken in the BB, through person to person interaction. The bank under study offers in-depth information, simulations, and pre-approval of mortgage loans in the IB service. But if some customers are able to search initial information in the Internet, they prefer to go to the bank branch when it comes to the evaluation of alternatives and negotiation.

Each essential use case has a specific set of functional requirements, which is well studied, given the long tradition of the banking industry. The development of new technologies has made it possible to satisfy these functional requirements through web interfaces, and has expanded the potential use of the Internet for service provision. However, it seems that, more than just making services functionally available in new channels, it is important to understand what customer experience requirements are associated with each essential use case, in order to understand what service channels are best suited to provide the desired service. 


\section{Conclusion}

This study shows that customers justify their preference for or avoidance of Internet banking, not so much in terms of functional attributes and technology features, but essentially in terms of experience requirements and general needs in a channelindependent way. These results suggest that the elicitation of customer requirements in multi-channel service can be improved through the application of essential use cases. As they are technology-independent, they allow a better understanding of customer needs, which designers can then use to develop interfaces which address customer requirements and make the best use of system capabilities. With this approach, service providers can make better decisions on what services are best suited to the Internet channel, to effectively address customer needs and offer a consistent service across different interaction modes.

\section{References}

1. Strauss, A. and Corbin, J.: Basics of Qualitative Research: Techniques and Procedures for Developing Grounded Theory. 2nd edn. Sage Publications, Thousand Oaks (1998)

2. Norman, D. A.: The Invisible Computer, 3rd printing. The MIT Press, Cambridge, Massachusetts (1998)

3. Shneiderman, B.: Designing the User Interface: Strategies for Effective Human-Computer Interaction. 3rd edn. Addison-Wesley, Reading, Massachusetts (1998)

4. Nielsen, J.: Designing Web Usability: The Practice of Simplicity. New Riders Publishing, Indianapolis (2000)

5. Preece, J., Rogers, Y. and Sharp, H.: Interaction Design: Beyond Human-Computer Interaction. John Wiley \& Sons, New York (2000)

6. Zeithaml, V. A., Parasuraman, A. and Malhotra, A.: Service Quality Delivery through Web Sites: A Critical View of Extant Knowledge. Journal of the Academy of Marketing Science, Vol. 30, No. 4 (2002) 362-375

7. Loiacono, E. T.: WebQual?: A Web site quality instrument. Unpublished doctoral thesis, University of Georgia (2000)

8. Nunes, N. J. and Cunha, J. F.: Whitewater Interactive System Development with Object Models. In: Harmelen, M. V. (ed.): Object Modeling and User Interface Design. AddisonWesley, Boston (2001) 197-244

9. Constantine, L. L., Lockwood, L. A. D.: Structure and Style in Use Cases for User Interface Design. In: Harmelen, M. V. (ed.): Object Modeling and User Interface Design. AddisonWesley, Boston (2001) 245-280

10. Solomon, M., Bamossy, G. and Askegaard, S.: Consumer Behaviour: A European Perspective, Financial Times Prentice Hall, Harlow (1998)

11. Patrício, L., Cunha, J. F. and Fisk, R. P.: Addressing Marketing Requirements in User Interface Design for Multiple Platforms, accepted for presentation in DSV - IS'2003 - 10th International Workshop on Design, Specification and Verification of Interactive Systems, Funchal (Madeira Island), Portugal, 4-6 June (2003) 